\title{
Analysis of Enterprise Management Model Innovation in the Era of Big Data
}

\author{
Faqiang Cui \\ Shandong Institute of Commerce \& Technology
}

Keywords: big data era; enterprise management mode; innovation measures

\begin{abstract}
With the rapid development of economy and the continuous improvement of science and technology level, the era of big data has arrived. In the face of this new situation, enterprises need to continue to improve themselves, innovation management model, and actively respond to the opportunities and challenges brought by the era of big data, to provide more economic and social benefits for the development of enterprises, thus promoting the healthy and sustainable development of enterprises. The first part of this paper describes the characteristics of the big data era and the profound significance it brings. The second part analyzes the problems brought about by enterprise management under the background of big data era, and discusses the reasons. Finally, in order to innovate enterprise management mode in big data era, specific solutions are put forward for existing problems.
\end{abstract}

\section{Basic Characteristics and Important Impact of Big Data}

First of all, big data, as the name suggests, has huge data and large amount of information. Among the basic characteristics of big data, the large amount of information is particularly significant and the most important feature. Large data is the processing, analysis and integration of all kinds of information. These data generally include all walks of life and all walks of life. Therefore, from the definition of large data, we can see that the amount of information is very large. With the continuous progress of society and the rapid development of science and technology, the era of big data has come, which has an important impact on people's work and life and so on, providing more data and information resources for the development of all walks of life.

Secondly, the information of large data is updated quickly. The existence and development of big data depend on the Internet, which also determines the speed of updating big data. Because the speed of Internet development and update is inestimable, the rapid development and update of the Internet will bring about an amazing speed of data information update, so one of the characteristics of large data is the rapid update speed. For example, when the data information of an industry is updated and increased, the information of big data will also increase after the Internet gets these new data information. At the same time, this means that every industry should keep a high vigilance at all times, and be good at collecting favorable information resources in the mass information so as to promote the effective development of its own.

In the end, big data brings a certain value. Because of the large amount of information in large data, the speed of data updating is very fast, which makes all walks of life can get a lot of valuable information in the process of using large data. For example, in the process of scientific and technological research, big data can provide effective data information and promote the effective implementation of scientific research. In the field of economic development, large data can also provide an improvement in efficiency and quality to promote economic development, and to present its own economic value in the economic development. Besides, in the aspect of social development, big data can provide more beneficial value for them. Work study, daily life and so on, large data create a lot of value, and a wide range of aspects, so it seems that the existence and development of large data will create a lot of value.

\section{Challenges and Problems Faced by Enterprise Management in Big Data Era}

In the context of the era of large data, in the process of collecting data, enterprises also collect 
data, such as pictures and video, in the Internet environment and e-commerce environment, in addition to traditional ways. From the management mode of enterprises at present, many enterprises take data processing methods only to deal with structured data information, but it is difficult to analyze and deal with unstructured data information. The key of the problem is that in the process of enterprise management, unstructured data is an important content, and improper handling will have a certain impact on the development of the enterprise. Thus, it is a challenge and difficult for enterprises to process diverse data information.

From the current point of view, many managers do not really realize the important role of large data and the value of the business, so the importance of large data is not very high. The managers of many enterprises in our country think that the large data is only simple data analysis and data sorting, and there is no important value for the management and development of the enterprise. Other companies believe that big data are not as valuable as financial statements. We are in the era of big data. Good use of big data can promote healthy and effective development of enterprises. However, with the arrival of the era of big data information, the channel of information is getting wider and wider, but it does not really play the role of large data. It is more difficult to pay attention to its value. It is difficult to promote the development trend of the enterprises.

The arrival of the era of big data has brought many opportunities for the development of enterprises, at the same time, it has also brought some hidden dangers for the development of enterprises. Whether it is social impact or the problem of staff operation, and the impact of viruses, it may bring serious problems to the information of enterprises. The data information of the enterprise involves many business secrets of the enterprise. This is a well-known problem. Once the problem of data security appears, it will cause serious harm to the enterprise. In recent years, business secrets have been leaked frequently, which is the main security problem in the era of large data, and it will have a serious negative impact on the survival and development of the enterprise.

All along, the survival and development of enterprises can not be separated from the support of talents. With the continuous progress of society, the demand for talents has also increased. With the advent of the era of big data, enterprises have encountered many problems and difficulties in terms of talent. Because the time of big data appears is not very long, and the corresponding talents are correspondingly lacking. From the present point of view, this kind of talent is trained by universities and society, but on the one hand, it is difficult to meet the needs of social development in the process of cultivating talents in many colleges and universities, often with theoretical knowledge as the main content and lack of practical training. On the other hand, the society lays particular emphasis on improving their practical skills in the process of cultivating talents, but neglects the cultivation of theoretical knowledge of the system, which leads to the lack of comprehensive ability for many talents. In the context of the era of large data, data processing and data analysis are particularly important, with high quality compound talents to promote the sustainable development of the enterprise. However, many enterprises in China have not paid much attention to this situation. Many traditional talents training methods have hindered the development of data talents.

\section{Related Suggestions for Enterprise Management Mode Innovation in Big Data Era}

With the advent of the era of large data, it has brought many opportunities and challenges for the development of enterprises. In addition to building a traditional traditional data platform, enterprises should pay more attention to the construction of an innovative data management platform. In other words, enterprises should set up a platform to deal with all kinds of unstructured data information, such as network pictures, videos and so on. At the same time, enterprises should not only fully excavate the content of data information, but also improve the search for data information. From the point of view of the data, the credibility of the enterprise is analyzed and the scientific and reasonable marketing means are formulated, so as to provide a strong data support for the business and development of the enterprise. Moreover, enterprises should also supervise data and information management, display product data information and service modes in a timely manner, and promote the timely and effective development of data management. In addition, enterprise managers should pay more attention to unstructured information in the mode of innovation 
management interface, integrate data information into various work links and carry out scientific and effective collection and processing, and build a comprehensive and systematic data base. In the end, when large data are used in the process of enterprise management and development, we need to take many forms to show all kinds of unstructured data information to the consumers, such as micro-blog, articles, pictures and so on, to fully display the enterprise products to the consumers and set up a good image for the development of the enterprise. Enterprises provide correct and effective ways to deal with information, grasp market trends in time, analyze market development situation, and innovate management mode according to their own conditions. Therefore, in the process of innovation in the era of big data, the enterprise management model should rely on large data and be good at applying large data to improve the management level and promote the sustainable development of the enterprise.

In the background of the era of big data, in the process of enterprise innovation management model, the managers of enterprises should fully realize the importance of large data and improve the importance of large data. In the process of operation and development, enterprise managers' ideology plays a decisive role in the decision-making and development of enterprises. Therefore, in the era of big data, we must change the managers' ideology when we innovate the management mode. The manager of the enterprise should judge the development situation of the market, and actively seek innovation and breakthrough point according to the current development situation, and combine the development and management characteristics of the enterprise itself, and the innovation management model. The traditional conservative management mode should be reformed and innovating, and will continue to develop under the environment of big data. The manager of the enterprise should truly realize the commercial value and important role of the big data age, and integrate the big data into all kinds of decision making of the enterprise and play the function and function of the big data. At the same time, the enterprise related technicians should keep the connection with the enterprise managers, communicate actively with them, and put forward specific suggestions on the important decision of the enterprise, so that the enterprise managers can realize the important role of the big data. When single data can not meet the development needs of enterprises, large-scale data analysis is needed to provide data support for the development of enterprises. Thus, in the process of enterprise innovation management in the era of big data, it is very important for leaders to improve the importance of large data, and to improve the management level of enterprises so as to promote the long-term development of the health of the enterprises.

In the face of big data era, enterprises should improve the management of information security, ensure the safety of enterprise data and information, and promote the healthy development of enterprises. First of all, enterprises should do a good job in preventing various natural disasters, for example, the computer will not be damaged by rain or lightning hazards, effective prevention of natural disasters, to provide a certain guarantee for the security of the enterprise's data and information security. Secondly, enterprises need to improve the supervision of data and information management personnel, prevent the phenomenon of divulging business secrets, and maintain the information security of enterprises. Finally, the enterprise also needs to provide protection measures to prevent virus and hacker attacks on the computer, for example, installing antivirus software and firewalls and antivirus software, checking data information regularly to ensure the security of data information. Thus, it can be seen that improving the management of information security can effectively prevent all kinds of dangerous occurrence, ensure the security of the data and information of the enterprise, and thus promote the healthy development of the enterprise. At the same time, enterprises need to backup and save important data information, prevent information stolen and lost, safeguard the interests of enterprises, and thus promote the sustainable development of enterprises.

In the era of big data, enterprises should improve the training of large data talents and cultivate more complex talents in the process of innovation management. However, in the process of cultivating talents, many colleges and universities focus on the training of students' professional knowledge and professional skills, and cultivate their awareness of competition between them, which is not conducive to the cultivation of students' ideas of innovation and development and team 
cooperation. Therefore, on the one hand, in the process of teaching reform, the information knowledge and technology of large data should be used scientifically and rationally, to improve the students' enthusiasm for learning and to cultivate their self-learning ability, so that students can learn the related content of large data by themselves. At the same time, we should introduce the content of large data into the teaching of professional courses, improve the students' data search ability, data integration ability, and information analysis ability, not only to improve the students' professional knowledge and skills, but also to provide more talent resources for the development of the society, so that students can enter the enterprise. When doing business, it can help enterprises to maximize their benefits and promote the healthy development of enterprises. On the other hand, in the process of cultivating large data talents, we should not only rely on the strength of colleges and universities, but also need the strong support of the state and society, and work together to cultivate more complex talents. In the era of big data, the state should give full play to its role and provide more institutional support and economic support for training talents. At the same time, colleges and universities in China also need to continuously strengthen communication and exchanges with enterprises and markets, so as to train more excellent talents for enterprises and society. In addition, China's colleges and universities can also introduce experts and teachers related to big data, so as to provide favorable teacher protection and knowledge and skills guarantee for training talents. Therefore, enterprises should actively cultivate large data personnel in the innovation management model, and train more complex talents through the joint efforts of the state and the society to provide talent protection for the development of the enterprises, thus promoting the sustainable development of our society.

\section{Conclusion}

With the advent of the era of big data, if enterprises want to occupy a favorable position in the unpredictable market environment, we should grasp the opportunities brought by the era of big data, actively respond to various challenges, and the most important thing is to constantly improve their own development forms. In the era of big data, enterprises innovate management mode, make full use of the advantages of the big data age to provide development opportunities for the development of enterprises, improve the application mode of large data knowledge, and improve the comprehensive strength and market competitiveness of the enterprises themselves. Although from the current situation of development, there are still some problems in the era of big data, lack of awareness of the era of big data, the lack of complex talents, and so on, but with the continuous improvement and development, enterprises will strengthen their own reform and innovation, and thus develop healthily and long in the fierce market competition.

\section{References}

[1] Jian R, Wang S B. Study on Innovation of Smart Library Service Model in the Era of Big Data[C]// International Conference on Electrical \& Electronics Engineering and Computer Science. 2016.

[2] Li T, Gao L. The future development of open innovation in the era of "Big Data”[J]. Science Research Management, 2016.

[3] Wang T. Research on Innovation Path of Enterprise Management Model in Big Data Era[J]. Journal of Hubei Correspondence University, 2017.

[4] Zhuang Y Y, Zhao Y G. Research on the Evolution Mechanism of Business Model Innovation System under the Era of Big Data: Taking Taobao as the Example[J]. Value Engineering, 2016.

[5] Li X, Feng X, University S N. Research On Business Model Innovation Of Sports Goods Enterprises In The Internet Era-Analysis Of The Development Dilemma Of Li Ning Company[J]. Journal of Anhui Sports Science, 2016.

[6] Yi-Yong Y U, Duan Y L, School I B. An Analysis of Enterprise Management Mode Innovation based on Big Data [J]. Technology \& Innovation Management, 2016. 